\title{
Bradley's Regress, Russell's States of Affairs, and Some General Remarks on the Problem
}

\author{
Holger Leerhoff \\ University of Konstanz \\ University of Oldenburg
}

In this paper, I will present Bradley's two main arguments against the reality of relations. Whereas one of the arguments is highly specific to Bradley's metaphysical background, his famous regress argument seems to pose a serious threat not only to ontological pluralism, but especially to states of affairs as an ontological category. Amongst the proponents of states-of-affairs ontologies, two groups can be distinguished: One group holds states of affairs to be complexes consisting of their particular and universal constituents alone, the other group holds that there has to be a "unifying relation" of some sort to establish the unity of a given state of affairs. Bradley's regress is often conceived to be a compelling argument against the first and for the latter. I will argue that the latter approaches have no real advantage over the simpler theories-neither in the light of Bradley's regress nor in other respects.

Keywords: ontology, Bradley, Russell

\section{Introduction}

Nowadays most analytic philosophers know F. H. Bradley's name primarily through his famous regress argument, Bradley's regress (sometimes also known as the 'instantiation regress' or the 'exemplification regress'). Although various and rather different presentations of the argument can be found in the literature-some of which would surely not appeal to Bradley himself-the regress argument indeed stems from Bradley, even though a closely related argument can be traced back through the middle ages to Plato in a more rudimentary form. ${ }^{1}$ Even though many analytic philosophers are not particularly fond of history, it is rather interesting to examine Bradley's regress argument in light of its historic context.

Corresponding author's address: Holger Leerhoff, Department of Philosophy, University of Oldenburg, 26111 Oldenburg, Germany. Email: holger@leerhoff.de.

1 See (Abaelardus 1970, 158f), and the first part of Plato's Parmenides. 
In the first part of this paper, I will focus on the regress argument in the context of Bradley's philosophy. In the second part, I will present a rough sketch of Russell's ontology from his Logical Atomism phase, which developed to a certain degree out of his severe criticism of Bradley's metaphysics. In the third part, I will discuss the problem from a more systematic point of view, trying to evaluate the force of Bradley's regress argument for states-ofaffairs ontologies akin to that of Russell.

\section{Bradley's idealistic monism}

Francis Herbert Bradley (1846-1924) was the most eminent British philosopher at around 1900; he may even be regarded as the greatest British philosopher between Mill and Russell. He belonged to the most influential philosophical school in turn-of-the-century Britain, the British Idealists, whose members dissociated themselves explicitly from the empiricist British tradition and took their inspirations from continental philosophers, especially from Kant and Hegel. Further important members of that school were Bernard Bosanquet, T. H. Green, Harold Joachim and J. M. E. McTaggart.

Bradley did important work in ethics, logic, and metaphysics, and in spite of the fact that he was extremely influential in his lifetime, his historic influence is rather meagre. From 1870 on he held a fellowship in Merton College, Oxford, with no teaching duties. Since he had a weak constitution, he led a rather reclusive life; R. G. Collingwood writes in his autobiography that he lived next door to Bradley in Oxford for about sixteen years without ever seeing him. ${ }^{2}$ Rumour has it that Bradley combined his affection for guns with his aversion to cats by going hunting in the college grounds at night. $^{3}$

Bradley's most important work in metaphysics is his Appearance and Reality (1893) where he distinguishes two spheres: appearance, consisting of those entities that are inconsistent, and reality, which is the consistent sphere. His Appearance and Reality consists of two books: the first, 'Appearance', is the destructive part and is intended to show that our whole being and knowledge is characterised by inconsistencies; the second part, 'Reality', is intended to give a description of the consistent sphere. According to Bradley, independently existing entities are the only entities that can be real and no object of our experience or thinking can fulfil this requirement. The one and only real entity is the Absolute (which is a kind of experience in the broadest sense). Bradley's metaphysics can therefore be characterized by the

2 See (Collingwood 1970, 16).

3 See (Candlish 2006); though I have no idea whether this is really true, it is too nice a detail to omit from this paper. 
motto "reality is one". All our ideas and all our objects of perception, even we ourselves, are no more than pragmatic useful abstractions of the Absolute and must be classified as mere appearance. It is not surprising that this has severe consequences for our thinking. In judging, we always refer to objects but are unable to grasp their "oneness": to have complete knowledge of an object, we would have to know what the object is as well as what it is not; but in order to know the latter, we would have to know the Absolute, which is impossible for us. So much for a very short glimpse of Bradley's theories. A closer look at Bradley's attitude towards relations will lead us to his regress argument.

According to Bradley, all relations are dyadic, i.e., holding between exactly two terms, and these two terms have to be different. So neither is identity a relation (due to the fact that its terms are not different) nor are relations between three or more terms counting as relations for Bradley. He argued that statements about relations cannot be (fully) true since there is only one single object. Bradley nevertheless held that relations are essential for epistemology and for common sense: all our judgements are relational, the objects of our experience are different from one another (and difference is a relation), and so on. Nonetheless, relations are not real, they belong to the sphere of appearance:

Relations, we saw, are a development of and from the felt totality. They inadequately express, and they still imply in the background that unity apart from which the diversity is nothing. Relations are unmeaning except within and on the basis of a substantial whole, and related terms, if made absolute, are forthwith destroyed. Plurality and relatedness are but features and aspects of a unity. (Bradley 1897, 125)

The core arguments of the first book of Appearance and Reality are directed against the reality of relations. Bradley goes as far as claiming that

[t]he reader who has followed and has grasped the principle of this chapter, will have little need to spend his time upon those which succeed it. He will have seen that our experience, where relational, is not true; and he will have condemned, almost without a hearing, the great mass of phenomena. (Bradley 1897, 29)

Bradley has two arguments to demonstrate the unreality of relations:

1. If the relation $R$ and its terms $a$ and $b$ were real, then there would be no way to explain how the relation between $R$ and $a, b$ could be established (see Bradley 1897, ch. II). This is the famous regress argument.

2. What is inconsistent has to be classified as appearance. Now, (i) terms presuppose relations (without the difference relation there could be 
only one term); (ii) relations presuppose terms (without at least two different terms there could be no relations). According to Bradley, (i) and (ii) are inconsistent, therefore relations belong to the sphere of appearance and are not real (see Bradley 1897, ch. III).

The second argument looks a bit weird at first, but an example can make things clearer. In order for there to be different colours, there has to be a relation of difference (or colour-difference). But such a relation can only exist if there are different colours beforehand! There can be no relation without there being relata, there can be no relata without there being a relation. It is a little bit like the hen-and-egg puzzle. This second argument is not very plausible and is very specific to the context provided by Bradley's metaphysics; it has been largely ignored, and I will gladly follow that tradition and focus on the first argument:

Here is the locus classicus for Bradley's regress argument:

... [the relation] being something itself, if it does not itself bear a relation to the terms, in what intelligible way will it succeed in being anything to them? But here $[. .$.$] we are hurried off into the eddy of$ a hopeless process, since we are forced to go on finding new relations without end. The links are united by a link, and this bond of union is a link which also has two ends; and these require each a fresh link to connect them with the old. The problem is to find how the relation can stand to its qualities; and this problem is insoluble. (Bradley 1897, 27f)

What Bradley actually says is this: Let us suppose that there are two entities $a$ and $b$ standing in a relation $R$ to each other: ${ }^{4}$

$a R b$.

According to Bradley, we are in need of a further relation actually uniting or, as he put it, "linking" the entities; let us call this relation L. Since Bradley held that all relations were dyadic, i.e., relating exactly two terms, we need not one $\mathrm{L}_{\text {but }} \mathrm{L}_{1}$ and $\mathrm{L}_{2}$ here, $\mathrm{L}_{1}$ linking $a$ to $R$ and $\mathrm{L}_{2}$ linking $R$ to $b$ :

$$
a \mathrm{~L}_{1} R \mathrm{~L}_{2} b \text {. }
$$

Now the problem is that $\mathrm{L}_{1}$ and $\mathrm{L}_{2}$ are themselves relations and are again in need of relations linking them to their respective terms. So there must be further linking relations $\mathrm{L}_{1}^{\prime}-\mathrm{L}_{4}^{\prime}$ :

$$
a \mathrm{~L}_{1}^{\prime} \mathrm{L}_{1} \mathrm{~L}_{2}^{\prime} R \mathrm{~L}_{3}^{\prime} \mathrm{L}_{2} \mathrm{~L}_{4}^{\prime} b \text {. }
$$

\footnotetext{
${ }^{4}$ I will use infix-notation here to make the matter clearer.
} 
On the next level we are in need of further linking relations $L_{1}^{\prime \prime}-L_{8}^{\prime \prime}$ to link the four $L^{\prime}$-relations to their respective terms. The whole matter gets more and more complex on each level without ever reaching an end, since every fresh linking relation must in turn be linked to its two terms. According to Bradley, the whole concept of relations is obviously inconsistent, and therefore relations cannot be real.

Bradley's exclusive use of dyadic relations makes the matter needlessly complicated, and one might suspect that at least part of the problem can be found here. Unfortunately, this is not the case, as the regress argument is not dependent on this rather anomalous constraint. Without it, the whole thing does indeed look simpler but the very same problem arises, as can be seen in this alternative formulation of the last formula:

$$
\mathrm{L}^{\prime}(\mathrm{L}(R a b)) \text {. }
$$

Here, we have only one (new) linking relation on each level, in each step of the regress. Nonetheless, you need a fresh $\mathrm{L}, \mathrm{L}^{\prime}, \mathrm{L}^{\prime \prime}$ etc. on each level to link the former relation to its terms, without ever reaching an end.

It is interesting to observe that Bradley's notion of relations supports his metaphysical monism: Suppose that $a$ and $b$ stand in the relation of coloursameness $G$ to each other: $G a b$. The entities $a, b$, and $G$ belong to the sphere of appearance, the whole concept of relations even is, as we have seen, inconsistent. According to Bradley it is better to regard the whole matter as a case of predication instead of relation: the larger object, the "sum"5 of $a$ and $b,[a b]$, has a property $E$, monochromacity, which corresponds to the apparent relation $G: E[a b]$. This way, the objects of appearance become larger and larger and thus come closer to the Absolute. Judgements about larger objects come can closer to the truth, but still no judgement can be absolutely true, since in every judgement object and property are necessarily separated. Pluralism and relations are indispensable in the sphere of appearance but nonetheless inconsistent; they are not real. Bradley's conception of relations leads to a fusion—or, at least, supports the combination—of idealism and monism.

Bertrand Russell and G. E. Moore were both raised in the time of British Idealism, and one of their teachers, McTaggart, was a famous member of that school. From 1898 onwards Russell and Moore argued against these two convictions, idealism and monism. This revolt is often regarded as the

5 It is not clear what exactly this "sum" is supposed to be; it is a kind of "larger" object consisting of $a$ and $b$. Since $a, b$ and their sum as well are no more than abstractions from the Absolute, it seems wrong to regard this sum as a mereological sum. In this paper, I will refer to this kind of sum by the use of its "parts" in square brackets. 
beginning of analytic philosophy. Generally speaking, Moore with his realism focused on idealism, Russell with his pluralism focused on monism. In the next part I will discuss some of Russell's arguments against Bradley's metaphysics.

\section{Russell's criticism}

Bradley's philosophy has some rather absurd consequences. Russell's criticism of Bradley can be found in his Principles of Mathematics and in an interesting discussion with Bradley in several issues of Mind from around 1910.

In Bradley's metaphysics, relations presuppose terms and terms presuppose relations; his alternative proposal, predication (the Doctrine of Internal Relations, as Russell calls it), is equally inconsistent. ${ }^{6}$ Even a predication of Bradley's only genuine object, the Absolute (e.g., 'The Absolute is real'), is necessarily inconsistent-so, obviously, you cannot have any true statements in this philosophical system. In mathematics, the situation is not any better, as even mathematical truths are not absolutely true. Russell, on the other hand, was certain that mathematical truths are "totally" true and that truth is not a matter of degrees. A further important point raised by Russell is that some indispensable relations cannot be converted to or translated into a subject-predicate form as suggested by Bradley. Confronted with Russell's criticism, Bradley explicitly accepted it and regarded the arguments as evidence for his philosophy, since appearance-where all this stuff belongs-is indeed inconsistent. It is extremely difficult to argue against such a position. Since Russell's criticism of Bradley's handling of relations is of utmost importance, I will present it in some more detail.

For the present context, asymmetric ${ }^{7}$ relations are of special interest: if $R a b$, then $\sim R b a$. Examples are relations such as '.. is larger than $\ldots$. ' ' $\ldots$ is earlier than ...'-relations which can establish an order; they are most important for mathematics.

According to Bradley, all relation statements are actually "disguised" subject-predicate statements. Hence, writes Russell, it must be possible to analyse all relation statements as statements in subject-predicate form. Two prominent ways have been opted for to analyse relation statements in this way:

Let some relation $R a b$ be given. It can be analysed as

${ }^{6}$ Properties, i.e., monadic relations, are equally subject to Bradley's regress argument, since a property has to be related to its term. Russell raises this point in (Russell 1996, \$53).

7 As a matter of fact, all antisymmetric relations could be used here, but for brevity's sake (and because it makes the matter clearer) I will confine myself to asymmetric (meaning antisymmetric and irreflexive) relations. 
1. $a$ and $b$ 's each having a different property "including" the other object: $R_{b}(a) \wedge R_{a}(b)$;

2. $a$ and $b$ 's constituting a (new) object having a certain property $P$ : $P[a b]$.

For some relations, these suggestions seem to provide an effective and convenient way of preserving the information given in a relation statement and transforming it into subject-predicate form. But let $R$ be an asymmetric relation and evaluate option (1). The objects $a$ and $b$ each have a different property "including" the other object: $R_{b}(a) \wedge R_{a}(b)$. Such a solution can be found in Leibniz: ' $a$ (is larger than) $b$ ' is analysed as ' $a$ (is larger than $b$ ) and $b$ (is not larger than $a$ )'. Analysed this way, the former relata become nonanalysable elements of new properties, even though they obviously should be analysable; the manner of reference "in" the properties remains obscure and it would be hard (to say the least) to make more general statements about structural properties of relations, e.g., formulating the criterion for transitivity. Furthermore, given one object with all its properties, all further objects would be somehow referred to by its properties. ${ }^{8}$ This is certainly an interesting and even information-preserving approach. However, it is not particularly valuable, as its complex properties cannot be analysed effectively. Let us have a look at option (2), which is Bradley's approach: The two relata $a$ and $b$ are replaced with their "sum" $[a b]$ (a "larger" object consisting of the two relata) and the supposed relation $R$ is analysed as a corresponding property $P$ 's applying to the new object (an example for this was given at the end of the preceding part). But if $R a b$ were indeed equivalent to $P[a b]$, then (since $[a b]=[b a]$ - the new object has no internal order or structure), Rab would be equivalent to $P[b a]$ and thus to $R b a$-the direction of the relation would be lost. So there would be no way of telling whether the analysed form of ' $a$ (is larger than) $b$ ', viz., ' $[a b]$ is $P$ ', means that $a$ is larger than $b$ or that $b$ is larger than $a$. In contrast to option (1), even the information expressed in the relation statement has been lost.

So, Bradley's approach is obviously unable to maintain the structural properties of relations, especially their "sense" or "direction" - which, in the case of antisymmetric relations, is a serious problem. Leibniz' approach fares better in regard to this aspect but has far-reaching problems in explaining the manner of reference involved in the complex "relational properties". To sum up, the traditional subject-predicate logic seems unfit to express what some types of relation statements express. According to Russell, a logic fit for handling relation statements has to be "atomic" or "pluralistic" and must supply a set of methods for working with relations.

\footnotetext{
${ }^{8}$ Of course, this reminds one of Leibniz' Monadology.
} 
But what has Russell to say with respect to Bradley's arguments against relations? Bradley's two arguments are supposed to be evidence against the reality of relations: (1) Bradley's regress, (2) relations and their terms presuppose each other. In the context of a pluralistic ontology like Russell's, argument (2) is quite harmless: both terms and relations belong to separate and (more or less) independent categories. According to Russell, the world consists of particulars, universals and-I will elaborate on that later-facts. There is not one thing, one single whole, but there is a plurality of different, independent entities. You do not have to ask whether the relata or the relation, the hen or the egg, came first; both are simply there.

Argument (1), one the other hand, seems to be far more serious. Even granted that there are particulars and relations as entities: each relation between two entities is again an entity-but what connects these entities, makes them a whole, establishes the unity of the fact? Even if there are $a, b$, and $R$, how can they form a unity, how can $R$ actually relate $a$ and $b$ ? Russell's solution of this problem reminds one of Frege's: According to Frege, relations are not really independent objects (like their relata) but unsaturated entities, in Russell's terminology: universals.

As an alternative to Bradley's Doctrine of Internal Relations, Russell presents his Doctrine of External Relations: On the linguistic side, we have the symbols $a, b$, and $R$, each denoting an entity "in the world." ' $R a b$ ' expresses that the two particulars $a$ and $b$ stand in the relation $R$ to one another; but $R$ is not a particular like $a$ and $b$, it is a universal, an unsaturated entity with as many "gaps" as particulars can be related by it. If there actually is a combination of $a, b$, and $R$ in the world, if ' $R a b$ ' is true, then $a$ and $b$ "saturate" $R$; the corresponding complex in the world is called a fact. No further "glue", no further linking relation is necessary to combine the entities. The saturation of the universal is not a further relation; the universal itself, as the relating relation of the fact, holds the fact together.

To sum up: In Russell, particulars do exist as independent entities; in addition to these entities, there are properties and relations-universals which, in Russell's terminology, subsist. ${ }^{9}$ Particulars have properties and stand in various relations to one another. It makes no difference to $R, a$, and $b$ as entities whether Rab or $\sim R a b$ is the case. The having of properties and the standing in relations to each another are facts. A fact is "[...] the kind of thing that makes a proposition true or false" (Russell 1989, 182); their existence is "a truism" (loc. cit.). Facts are objective objects in the world, and form a third ontological category. They are more than the sum of their components. What holds facts (or, to use a more common expression, states of affairs) together, what establishes their unity, are the unsaturated universals

9 This is only a matter of terminology, not of 'gradual existence'. 
as relating relations.

This proposal of Russell has one serious flaw. According to the early Russell of the Principles, every denoting phrase denotes an existing entity in the world. ${ }^{10}$ Now take the following case: (A) ' $a$ is red' - the saturated particular $a$ has the unsaturated property (universal) of being red. (B) 'red is not blue'-the saturated entities red and blue stand in the unsaturated relation (universal) of being different to each other. How is it possible that red is an unsaturated entity in (A) and a saturated entity in (B)? And is this saturated entity a particular or another kind of universal? According to Russell, only the actual relating relation - the "top-level relation"- of the state of affairs is unsaturated; this is not satisfying, since it remains in the dark what, e.g., saturated red is supposed to be: both particular and universal? The matter reminds one of Frege's argument with Kerry in Über Begriff und Gegenstand (Concept and Object); there seem to be concepts which fall under another concept. ${ }^{11}$

With his Theory of Descriptions from 1905, Russell developed the idea of incomplete symbols: Many words and expressions, e.g., descriptions (both definite and indefinite), class expressions, predicates and relation expressions, do not denote entities. Taken in isolation, these expressions are even meaningless. They can be evaluated only in the context of a proposition: 'the present rector of the University of Tartu' is meaningless; 'The present rector of the University of Tartu exists', on the other hand, is meaningful (and a true statement about Alar Karis). Now, predicates and relation expressions have to be interpreted as incomplete symbols, too, not as names for properties and relations, i.e., for universals. According to this theory, 'Red is not blue' is not a proposition about universals but about particulars: all that is said is that there is no particular that is both (completely) red and (completely) blue. The correct symbol for a putative property or relation is the symbol for a propositional function like ' $\hat{y}$ is red'-expressed this way, their unsaturatedness is made explicit. ${ }^{12}$ Russell's Theory of Types is a perfect device to explain Frege's notion of second (or, more general, different) order concepts. Taken this way, the double-role problem vanishes.

Russell's logic is much more compatible with common sense than the traditional subject-predicate logic and also able to cope with all kinds of relation statements. It suggests a radically different ontology, with particu-

${ }^{10}$ See, e.g., (Russell 1996, $\$ \$ 46 f$ )

${ }^{11}$ See (Frege 1892).

${ }^{12}$ See, e.g, (Whitehead and Russell 1962, Introduction, ch. III). Nonetheless, the ontological status of propositional functions is by no means clear. There might be universals corresponding to some propositional functions-Russell himself would surely subscribe to this-but the device of propositional functions allows for predicates and relation expressions which do not correspond to any universal. 
lars, universals and facts (states of affairs) as distinct ontological categories; Russell's ontology is a states-of-affairs ontology (not unlike Wittgenstein's in the Tractatus). Russell and Wittgenstein both realised the threat posed by Bradley's regress and were convinced that their systems were not subject to it. Russell's universals as well as Wittgenstein's Gegenstände are unsaturated entities: both philosophers saw no need to have any further "linking" relations to explain the unity of their states of affairs.

\section{Bradley's regress and states of affairs}

Assessments of Bradley's regress differ extraordinarily. On the one hand, one finds quotations like this one:

Charity bids us avert our eyes from the pitiable spectacle of a great philosopher using an argument which would disgrace a child or a savage. (Broad 1933, 85)

On the other hand, Bradley's regress is discussed again and again as a plausible argument against states-of-affairs ontologies. In this section, I will discuss two approaches to the regress problem brought forward by proponents of such theories. From one standpoint, we see positions like the one sketched above, taken e.g. by Russell, the Tractatus-Wittgenstein, and D. M. Armstrong. ${ }^{13}$ These authors consider Bradley's regress as more or less a nonissue: they regard the unity of a state of affairs as a brute fact. From another standpoint, many authors try to escape the threat posed by the regress argument by postulating a special kind of exemplification relation which does establish the unity of states of affairs but is not itself in need of further linking relations, so that the the regress is stopped once the unity is established. Before discussing these two approaches, it is valuable to investigate whether Bradley's regress is a serious problem at all.

In the literature, Bradley's regress is sometimes classified as a virtuous regress, sometimes (and more often) as a vicious one. Furthermore, it can be observed that there is no consensus regarding the actual area in which the regress occurs: in propositions or in states of affairs. The regress seems to be more serious in the area of states of affairs (since propositions are somewhat dubious entities anyway), so I will concentrate on that area. If one classifies the regress as vicious, surely an alternative is called for. But even a virtuous regress is something one would want to avoid, if possible.

${ }^{13}$ At least I take this to be the position Armstrong puts forward in (Armstrong 1989a, 1989b, 1997). In (Armstrong 2004) he adopts a position akin to that of Donald Baxter and regards states of affairs as entities which kind of 'supervene' on their constituent particulars and universals; I will not discuss that approach here. 
To illustrate at which points the two approaches mentioned above attack Bradley's regress argument, I want to offer the following crude reconstruction of the argument. I think that Bradley's regress can be regarded as resulting from the combination of two principles: ${ }^{14}$

(P1) When particulars and universals are related then there has to be a further relation which does the linking.

(P2) Relations are universals.

Now, suppose that

$a$ and $b$ are related by $R$ (e.g., ' $a$ is larger than $b$ '); then

there has to be an $\mathrm{L}$ such that $\mathrm{L}(R a b)$ (with $\mathrm{P} 1)$;

$\mathrm{L}$ is a universal (with $\mathrm{P}_{2}$ );

there has to be an $\mathrm{L}^{\prime}$ such that $\mathrm{L}^{\prime}(\mathrm{L}(R a b))$ (with $\left.\mathrm{P} 1\right)$;

$\mathrm{L}^{\prime}$ is a universal (with $\mathrm{P}_{2}$ );

there has to be an $\mathrm{L}^{\prime \prime}$ such that $\mathrm{L}^{\prime \prime}\left(\mathrm{L}^{\prime}(\mathrm{L}(R a b))\right)$ (with $\left.\mathrm{P} 1\right)$;

Let us have a look at some of the options to escape this regress:

1. Principle $\left(\mathrm{P}_{1}\right)$ can be attacked: there is no exemplifying relation doing the linking, the universals as "relating relations" are doing the trick by themselves.

2. Principle ( $\left.\mathrm{P}_{2}\right)$ does not hold for the exemplification relation; the first step of the regress must be taken, but the result is a unit not held together anymore by a universal but rather by a special kind of relation.

The first option is taken by Russell and, until recently, by Armstrong. Wittgenstein's solution ("In a state of affairs, the objects hang one in another like the links in a chain", Wittgenstein 1974, 2.03) can be regarded as being

\footnotetext{
${ }^{14}$ I do not intend to give a universal reconstruction of the argument. Bradley's regress can occur in lots of areas (states of affairs, propositions etc.) and can be regarded as an argument against a lot of different ontological systems. Furthermore, some systems are "immune" to the regress due to other reasons (e.g., Armstrong's most recent approach and ontologies based on non-transferable tropes have states of affairs as entities which kind of "supervene" on their constituents). I will confine myself to plain-vanilla cases here-the two principles are only intended to illustrate two common ways of arguing against Bradley's regress.
} 
closely related to this, though he does not talk about particulars and universals in the Tractatus. According to this first approach, it is it is a mere façon de parler to say that $a$ and $b$ "exemplify" or "instantiate" $R$. All that is being said is that $R a b$ is the case. Not every relation expression (amongst others, 'exemplifies') has a corresponding relation. The unity of the state of affairs is an ontologically brute fact.

Proponents of the second option say that the constituents of a state of affairs are linked by an internal "non-relational tie" (Strawson), a "nexus" (Bergmann), a "fundamental tie" (as Armstrong calles it), a certain relation of exemplification to establish the specific state of affairs. It is important to observe that these "unifying relations", as I want to call them, are supposed not to be universals like ordinary relations are. This way, the regress cannot take off (since ( $\left.\mathrm{P}_{1}\right)$ does not apply to the unifying relation). Strawson and Bergmann explicitly mention Bradley's regress as the reason for their relating entities not being universals. ${ }^{15}$

Why should one opt for such a solution instead of the brute-fact approach? Can such a unifying relation be useful-that is, apart from "explaining" in an ontological sense that a state of affairs forms a unity? Two issues spring to mind.

The first is that Russell's unsaturated universals are a bit hard to grasp. Could one get around these entities? As we have seen, Bradley's regress can be stopped with option 2: the unifying relation is a special kind of relation, and maybe it could take over the unsaturatedness from the universals without being a universal itself. Again, antisymmetric relations seem to pose a serious problem for this approach. Suppose that we have a unifying relation $\mathrm{L}$, a "saturated universal" $R^{\star}$ and two particulars $a$ and $b$. Due to the unsaturatedness of $\mathrm{L}$, we could have a state of affairs $\mathrm{L}\left(R^{\star} a b\right)$. Now, the difference between $R^{\star} a b$ and a corresponding state of affairs with an unsaturated $R$, i.e., $R a b$, is a bit hard to grasp. Can a saturated universal have a direction, a sense? In writing down and reading symbols we are accustomed to interpret them as standing in a certain relation already, so $R^{\star} a b$ suggests that $a$ is coming first, is standing in $R^{\star}$ to $b$. In talking about unsaturated relations, we can suppose that $R$ has a "front gap" and a "back gap". Your putting a specific particular in each of these gaps can explain why the two states of affairs $R a b$ and $R b a$ are different-in the one case, $a$ occupies the front gap and $b$ occupies the back one, in the other case the roles are reversed. A saturated universal has no gaps, no direction, so how can $R^{\star} a b$ and $R^{\star} b a$ be distinguished? Maybe this is soluble by introducing some further non-universal connector relations, but that would be rather intricate.

${ }^{15}$ See (Strawson 1990, 167; Körner 1968, 65f) 
The second issue is that a state of affairs is different from the mereological sum or the set of its constituents. Could a unifying relation provide means to use one of these less problematic complexes instead of states of affairs? A mereological sum has no structure; the states of affairs $R a b$ and $R b a$, taken as sums $(R+a+b)$ of their constituents, could not be distinguished. A unifying relation as a further component would make no difference. Sets are no better off: A set has no structure; the states of affairs Rab and Rba, taken as sets $(\{R, a, b\})$, could not be distinguished. Again, a unifying relation as a further element would make no difference to the matter. As in the first issue, the structure of the state of affairs is the problem here.

It seems that, regarding states of affairs, two phenomena are particularly peculiar:

1. How can a state of affairs be a unit?

2. How can a state of affairs have a structure?

The approaches which work with some kind of unifying relation-at least the ones I know of-claim to give a better explanation for the unity problem (1) than the brute-fact approach does, where the unsaturated universals as relating relations establish the unity of the state of affairs. In my opinion they fail to do so. To be sure, the talk about the unsaturatedness of the universals and about "gaps" seems to be a kind of metaphor, but I do not think that anything better can be said about their competitors. Furthermore, the alternative approaches only take the whole problem one step further: that there is a nexus, a non-relational tie, or whatever, uniting $a, b$, and $R$ to the state of affairs $R a b$, surely is a way to answer the ontological question of how the unity of a state of affairs is established. But one could ask again how the nexus or the non-relational tie unites these entities. The answer to this question can hardly be more satisfactory than the criticised answer of the brute-fact proponents. An additional problem is that the alternatives fail to give an explanation of the direction problem (2) or have to resort to unsaturated universals (like the brute-fact approach does) or weird connector relations for this purpose.

So far, there seem to be no really compelling reasons for accepting any sort of unifying relation. In spite of that, some authors think that one cannot do without such a relation; they defend their case by offering arguments against the brute-fact approach. One of the most radical defenders of such a unifying relation (though of a different kind as discussed here) is William Vallicella. In his (Vallicella 2002) he offers three arguments against the brutefact approach:

1. According to the brute-fact approach, the state of affairs $R a b$ can be analysed to have the constituents $R, a$, and $b$ (and no further con- 
stituents). Nonetheless, the existence of $R, a$, and $b$ does not entail the existence of $R a b$ : the state of affairs $R a b$ is a further entity in addition to them and irreducible to them. Now Vallicella states, taking the side of David Lewis, ${ }^{16}$ that it is contradictory to say of a whole that it is an entity over and above its parts when it is composed of them. ${ }^{17}$ No matter how hard I try, I cannot see any contradiction here.

2. How can states of affairs be recognised as states of affairs, what do they have in common? Vallicella argues that if one had a further entity (e.g., a unification relation) as a component in every state of affairs, that could do the trick. Since the states of affairs in the brutefact approach do not have such a common entity, the approach must fail. ${ }^{18}$ Against that, it seems to me that states of affairs can be recognised by their being complex entities. Mereological sums and classes are complex too, but they are not part of the "genuine ontological existents" - so, states of affairs are (and perhaps have to be?) the only ontological complexes around.

3. According to the brute-fact approach, two states of affairs can have the very same constituents but nonetheless be different: Rab vs. Rba. Vallicella claims that it is not possible that complexes consisting of the same constituents differ, as can be seen in mereological sums and sets. ${ }^{19}$ Though the sets $\{R, a, b\}$ and $\{R, b, a\}$ as well as the sums $R+a+b$ and $R+b+a$ are indeed identical, the states of affairs $R a b$ and $R b a$ are not: It does make a difference whether $a$ is larger than $b$ or $b$ is larger than $a$. And this difference is not a matter of some (additional) components or external unifiers but rather one of the structure of these states of affairs, which is, again, not reducible to its components.

Let us have a final look at some of the features of the brute-fact approach: The resulting ontological system is very parsimonious but nonetheless powerful. There are no classes (Russell's No-Class Theory), no mereological sums (in Armstrong, these are supervening entities-an "ontological free lunch"), no "exemplification", "instantiation", "unification" or whatever as a relation or operator leading a kind of shadow-existence by being a non-universal relation. The unity and the structure of states of affairs are brute facts: what establishes their unity and their structure (and allows us to tell $R a b$ from $R$,

\footnotetext{
${ }^{16}$ See (Lewis 1992, 213).

${ }^{17}$ See (Vallicella 2002, 20f).

${ }^{18}$ See (Vallicella 2002, 21f).

${ }^{19}$ See (Vallicella 2002, 22ff).
} 
$a, b$ and from $R b a$ ) cannot be explained. States of affairs are a third ontological category in addition to particulars and universals.

\section{Concluding remarks}

In the historical context, the discussion about Bradley's regress shows that Bradley's treatment of relations was rather clever and that he recognised the importance of relations for our understanding of the world. Contrary to what can often be read, his regress argument was not intended to show that "internal" relations are a suitable alternative to "external" relations (as, e.g., Russell presents the argument). Bradley's criticism focused on pluralism (in his Appearance and Reality) and on states of affairs (in his later discussion with Russell); he held both to be impossible.

In the systematic context, the discussion about Bradley's regress shows that ontologies with states of affairs (not "supervening" on non-transferable tropes, partially identical particulars and universals, etc.) are still subject to Bradley's challenge and that there is no generally accepted solution to the problem. In my opinion, the approaches including a kind of non-universal unifying relation have no significant advantage over the clear and parsimonious brute-fact approach that can be found in, amongst others, Russell (during his Logical Atomism and early Neutral Monism period) and, until recently, in Armstrong. So, with Occam's razor, we should opt for the simpler approach.

\section{Acknowledgements}

This paper draws on results from an ongoing research project commissioned by the Landesstiftung Baden-Württemberg.

\section{Bibliography}

Abaelardus, P. (1970). Dialectica, van Gorcum \& Comp, Assen.

Armstrong, D. M. (1989a). A Combinatorial Theory of Possibility, Cambridge University Press, Cambridge.

Armstrong, D. M. (1989b). Universals. An Opinionated Introduction, Westview, London, Boulder (Colorado).

Armstrong, D. M. (1997). A World of States of Affairs, Cambridge University Press, Cambridge.

Armstrong, D. M. (2004). Truth and Truthmakers, Cambridge University Press, Cambridge. 
Bradley, F. H. (1897). Appearance and Reality-A Metaphysical Essay, Vol. 9 of Collected Works, 2nd edn, Thoemmes Press, Bristol, Sterling (Virginia).

Bradley, F. H. (1910). On appearance, error and contradiction, Mind 19: 153185.

Bradley, F. H. (1911). Reply to Mr. Russell's explanations, Mind 20: 74-76.

Broad, C. D. (1933). An Examination of McTaggart's Philosophy, Cambridge University Press, Cambridge.

Candlish, S. (2006). Francis Herbert Bradley, in E. N. Zalta (ed.), The Stanford Encyclopedia of Philosophy, fall $2006 \mathrm{edn}$.

URL: http://plato.stanford.edu/archives/fall20o6/entries/bradley/

Collingwood, R. G. (1970). An Autobiography, Oxford University Press, London.

Frege, G. (1892). Über Begriff und Gegenstand, Vierteljahrsschrift für wissenschaftliche Philosophie 16: 192-205.

Körner, S. (1968). Discussion: On Bergmann's ontology, Philosophy of Science 35/1: 64-71.

Lewis, D. (1992). Critical notice of Armstrong, D. M., A Combinatorial Theory of Possibility, Australasian Journal of Philosophy 70/2: 211-224.

Russell, B. (1910). Some explanations in reply to Mr. Bradley, Mind 19: 373378.

Russell, B. (1989). The philosophy of logical atomism, in B. Russell (ed.), Logic and Knowledge-Essays 1901-1950, Unwin Hyman, pp. 177-281.

Russell, B. (1996). The Principles of Mathematics, W. W. Norton, New York, London.

Strawson, P. F. (1990). Individuals, Routledge, London.

Vallicella, W. F. (2002). Relations, monism, and the vindication of Bradley's Regress, Dialectica 56: 3-36.

Whitehead, A. N. and Russell, B. (1962). Principia Mathematica to ${ }_{5} 56$, Cambridge University Press, Cambridge.

Wittgenstein, L. (1974). Tractatus Logico-Philosophicus, Routledge and Kegan Paul, London. Trans. C. K. Ogden. 